\title{
Movement-Related Discharge in the Macaque Globus Pallidus during High-Frequency Stimulation of the Subthalamic Nucleus
}

\author{
Andrew J. Zimnik, ${ }^{1}$ Gerald J. Nora, ${ }^{1}$ Michel Desmurget, ${ }^{2}$ and ${ }^{\circledR}$ Robert S. Turner ${ }^{1}$ \\ ${ }^{1}$ Department of Neurobiology, Center for the Neural Basis of Cognition, University of Pittsburgh, Pittsburgh, Pennsylvania 15261, and ${ }^{2}$ Centre for Cognitive \\ Neuroscience, UMR5229, CNRS, 67 Boulevard Pinel 69500 Bron, France
}

\begin{abstract}
Deep brain stimulation (DBS) of the subthalamic nucleus (STN-DBS) has largely replaced ablative therapies for Parkinson's disease. Because of the similar efficacies of the two treatments, it has been proposed that DBS acts by creating an "informational lesion," whereby pathologic neuronal firing patterns are replaced by low-entropy, stimulus-entrained firing patterns. The informational lesion hypothesis, in its current form, states that DBS blocks the transmission of all information from the basal ganglia, including both pathologic firing patterns and normal, task-related modulations in activity. We tested this prediction in two healthy rhesus macaques by recording single-unit spiking activity from the globus pallidus (232 neurons) while the animals completed choice reaction time reaching movements with and without STN-DBS. Despite strong effects of DBS on the activity of most pallidal cells, reach-related modulations in firing rate were equally prevalent in the DBS-on and DBS-off states. This remained true even when the analysis was restricted to cells affected significantly by DBS. In addition, the overall form and timing of perimovement modulations in firing rate were preserved between DBS-on and DBS-off states in the majority of neurons (66\%). Active movement and DBS had largely additive effects on the firing rate of most neurons, indicating an orthogonal relationship in which both inputs contribute independently to the overall firing rate of pallidal neurons. These findings suggest that STN-DBS does not act as an indiscriminate informational lesion but rather as a filter that permits task-related modulations in activity while, presumably, eliminating the pathological firing associated with parkinsonism.
\end{abstract}

Key words: basal ganglia; nonhuman primate; reaching

\section{Introduction}

Deep brain stimulation (DBS) of the basal ganglia (BG) has largely supplanted ablation (Esselink et al., 2004) as a treatment for Parkinson's disease (PD). Despite the similar therapeutic effects of lesions of the subthalamic nucleus (STN) or globus pallidus internus (GPi) and stimulation of these nuclei (Limousin et al., 1995; Alvarez et al., 2001; Rodríguez-Oroz et al., 2005; Merello et al., 2008), evidence indicates that different local mechanisms are responsible for the therapeutic effects of these two treatments. Rather than mimicking a lesion by silencing neuronal activity around the site of stimulation in the STN or GPi (Benazzouz et al., 2000; Dostrovsky et al., 2000; Meissner et al., 2005), recent studies have shown that DBS has a complex effect on the

Received Dec. 2, 2014; revised Jan. 21, 2015; accepted Jan. 23, 2015.

Author contributions: R.S.T. designed research; A.J.Z. and M.D. performed research; A.J.Z., G.J.N., and R.S.T. analyzed data; A.J.Z., G.J.N., and R.S.T. wrote the paper.

This work was supported by the National Institute of Neurological Disorders and Stroke at the National Institutes of Health Grants R01NS044551 and R01NS070865 to R.S.T. and the Center for Neuroscience Research in Non-human primates 1P30NS076405-01A1. We thank Steve Sargent for contributions to animal care; Richard Dum for assistance obtaining the anatomical figures; Matt Panico and Benjamin Pasquereau for critiques of the manuscript; and Robert Rosenbaum for contributions to the analysis methods.

The authors declare no competing financial interests.

Correspondence should be addressed to Robert S. Turner, Department of Neurobiology, University of Pittsburgh, 4047 BST-3, 3501 Fifth Avenue, Pittsburgh, PA 15261. E-mail: rturner@pitt.edu.

DOI:10.1523/JNEUROSCI.4899-14.2015

Copyright $\odot 2015$ the authors $\quad 0270-6474 / 15 / 353978-12 \$ 15.00 / 0$ activity of local neurons, which includes increases or decreases in firing rate and/or phasic entrainment of firing to the stimulation frequency (Bar-Gad et al., 2004; McCairn and Turner, 2009; Carlson et al., 2010; Moran et al., 2012).

To explain how two distinct interventions (ablation and highfrequency electrical stimulation) can yield similar therapeutic effects, researchers have proposed that DBS creates an "informational lesion" (Grill et al., 2004; Garcia et al., 2005; Dorval et al., 2008, 2010; Guo et al., 2008; McConnell et al., 2012; Rubin et al., 2012; Agnesi et al., 2013). This theory posits that DBS induces highly regular, stimulus-driven spiking activity (i.e., "entrained" spiking) in populations of BG neurons, impeding the transmission of "information" (encoded in neuronal spiking) from the BG to thalamus. By replacing pathologic activity with stimulusentrained firing patterns, a DBS-induced informational lesion would ameliorate parkinsonian signs by blocking the transmission of interfering signals to downstream structures. General support for the informational lesion hypothesis has come from studies of the effects of DBS on the theoretical information capacity of spontaneous neuronal activity (i.e., the firing rate "entropy") (Dorval et al., 2008, 2009, 2010) and a study of the transmission of stimulation-evoked cortical volleys (Chiken and Nambu, 2013).

In addition to supplanting pathologic resting activity, a DBSinduced informational lesion is predicted to block the transmis- 
sion of normal task-related modulations in activity (Dorval et al., 2010; Chiken and Nambu, 2013). Recent work has cast doubt on this assumption. Agnesi et al. (2013) reported that DBS in the GPi attenuates specific aspects of the neuronal encoding of proprioceptive sensory information and Dorval and Grill (2014) that STN-DBS increases resting directed entropy within the BG in rats. We tested a different aspect of the informational lesion prediction by examining the effects of STN-DBS on the activity of GP neurons around the time of active reaching movements. It is important to note that the present study asks whether normal task-related modulations in firing rate are preserved during STNDBS. Although DBS is used to treat neurologic disorders, the question at hand cannot be addressed well in an animal model of such a disorder (e.g., parkinsonism) because abnormalities in task-related activity are likely to accompany the disorder. For example, the normal high degree of selectivity of GP activity (often responding to only one direction of movement at one joint) is severely degraded in parkinsonism, leading to a loss of functional segregation (Filion et al., 1988, 1989; Boraud et al., 2000). Thus, if an animal model of parkinsonism was used, it would not be possible to distinguish DBS-induced loss of normal task responsiveness (i.e., support for the informational lesion hypothesis) from DBS-induced restoration of functional segregation (a potential component of the normal therapeutic effect of DBS).

Our results indicate that not only do task-related modulations in pallidal spike rate persist during STN-DBS, but the specific timing and shape of movement-related modulations in firing rate are also largely preserved. The modulations in GP firing rate induced by STN-DBS and active movement interacted significantly in only a small fraction of cells, most of which were highly entrained to the STN-DBS stimulus pulse. These results suggest that movement-related signaling in the GP is degraded by STN-DBS only in the infrequent occasion that DBS-induced entrainment drives a GP cell to its physiologic limits.

\section{Materials and Methods}

Animals and task. Two monkeys (Macaca mulatta; Monkey B, male $15 \mathrm{~kg}$; Monkey D, male $8.2 \mathrm{~kg}$ ) were used in this study. All aspects of animal care were in accord with the National Institutes of Health Guide for the Care and Use of Laboratory Animals, the PHS Policy on the Humane Care and Use of Laboratory Animals, and the American Physiological Society's Guiding Principles in the Care and Use of Animals. All procedures were approved by the institutional animal care and use committee. The monkeys performed a unimanual version of a reaching task that has been described in detail previously (Franco and Turner, 2012). In brief, the animal was seated in a primate chair facing a vertical response panel that contained two target LEDs and infrared proximity sensors. The animal's working hand rested on a "home-key" (a metal rod, also equipped with an infrared proximity sensor) located at waist height on the same side of the primate chair. The opposite arm was left unrestrained and uninvolved in the task. Monkey D performed the task with the right arm, whereas Monkey B performed the task with the left arm. The task required the animal to hold its hand on the home-key for 2.6-4.8 s (uniform random distribution) at which time the right or left LED (selected at random) was illuminated. The animal was given $1 \mathrm{~s}$ to move its hand from the home-key to the target indicated. Once the correct target was contacted, the animal was required to hold its hand at the target for $0.5-1.0 \mathrm{~s}$ (randomized) before a food reward was delivered via a sipper tube and a computer-controlled peristaltic pump. The animal was then allowed to return its hand to the home-key with no time limit.

Surgery. Many of the surgical methods have been described previously (Desmurget and Turner, 2008). The chamber implantation surgery was performed under sterile conditions with ketamine induction followed by isoflurane anesthesia. Vital signs (i.e., pulse rate, blood pressure, respiration, end-tidal $\mathrm{pCO}_{2}$, and $\mathrm{EKG}$ ) were monitored throughout the dura- tion of the surgery to ensure proper levels of anesthesia. In Monkey D, two cylindrical titanium recording chambers (18 $\mathrm{mm}$ inside diameter) were affixed over craniotomies at stereotaxic coordinates to allow access to the left globus pallidus via a coronal approach and left subthalamic nucleus via a parasagittal approach. In Monkey B, a single recording chamber was affixed over a craniotomy to allow access to the right subthalamic nucleus and pallidum via a parasagittal approach. The chambers and head fixation devices were fastened to the skull via bone screws and methyl methacrylate polymer. Prophylactic antibiotics and analgesics were administered postsurgically.

Localization of stimulation and recording sites. The anatomical locations of the STN and GP and proper stereotaxic positioning of the recording chambers were estimated initially from structural MRI scans (Siemens $3 \mathrm{~T}$ Allegra Scanner, voxel size of $0.6 \mathrm{~mm}$ ). An interactive 3D software system (Cicerone) was used to visualize MRI images, define the target location, and predict trajectories for microelectrode penetrations (Miocinovic et al., 2007; Pasquereau and Turner, 2013). By aligning microelectrode mapping results (electrophysiologically characterized $x, y, z$ locations) with structural MRI images and high resolution 3D templates of individual nuclei derived from an atlas (Martin and Bowden, 1996), we were able to gauge the accuracy of electrode positioning. This approach was used to determine the chamber coordinates for the implantation of STN DBS electrodes (Fig. $1 A$ ) and for the subsequent recording tracks in the GP.

Implantation of indwelling DBS electrode. The methods used to implant an indwelling macroelectrode have been described previously (Turner and DeLong, 2000). Custom-built stimulating electrodes were implanted in the left STN of Monkey D and the right STN of Monkey B (i.e., in the hemisphere contralateral to the working arm). The electrode consisted of three Teflon-coated Pt-Ir microwires (50 $\mu \mathrm{m}$ diameter) glued inside a stainless steel cannula $(\sim 0.5 \mathrm{~mm}$ separation between the distal ends of the microwires). The insulation was stripped from $\sim 0.2 \mathrm{~mm}$ of the distal ends of the microwire such that the impedance of the wires was between 4 and $19 \mathrm{k} \Omega$ (exposed surface area $\sim 0.03 \mathrm{~mm}^{2}$ ). The electrode assembly was implanted transdurally via the sagittal chamber using a protective guide cannula (28-gauge inside diameter) and stylus mounted in the microdrive. The location of the electrode was monitored as it was lowered using multiunit activity sampled from the most distal electrode contact. Once the electrode was located within the STN, the guide tube and stylus were withdrawn so that the electrode assembly remained at the desired location, with the proximal ends of the microwires exiting the dura. The proximal ends of the microwire were guided through a port in the side of the recording chamber and soldered to a head-mounted connector. Following implantation of the electrode assembly, the threshold stimulation current ( $1 \mathrm{~s}$ duration train at $150 \mathrm{~Hz}$ ) for evoking movement or palpable muscle contraction (via excitation of the fibers of the internal capsule) was determined. Stimulation at currents up to $80 \%$ of this value was used in subsequent experiments to stimulate the largest volume of STN possible without eliciting muscular contractions.

Data acquisition and artifact subtraction. The procedures used for data acquisition and artifact subtraction have been described previously (McCairn and Turner, 2009). In brief, the extracellular spiking activity of globus pallidal neurons was recorded using glass-insulated tungsten microelectrodes (0.5-1.5 $\mathrm{m} \Omega$, Alpha Omega) mounted in a hydraulic microdrive (MO-95, Narishige International). Data were passed through a low-gain headstage (gain $=4 \times, 2 \mathrm{~Hz}$ to $7.5 \mathrm{kHz}$ bandpass) and then digitized at $24 \mathrm{kHz}$ (16-bit resolution; Tucker Davis Technologies) and saved to disk as continuous data. During data collection, the neuronal recording was monitored by computer display and by $\mathrm{D} / \mathrm{A}$ conversion and playback on a digital oscilloscope and audio monitor.

During high-frequency DBS, on-line signal processing (Tucker Davis Technologies) was used to adaptively subtract the stimulation-induced electrical artifacts from the digitized neuronal data (McCairn and Turner, 2009). A stimulation artifact template was constructed as a moving average of the 100 immediately preceding shocks. This template was automatically and continuously subtracted from the digitized neuronal signal at the time of each DBS shock.

Recording and stimulation protocol. All recordings were performed using a single microelectrode lowered transdurally into the pallidum. All 
recordings in Monkey D were performed using a coronal approach in the left hemisphere, whereas all recordings in Monkey B were performed using a parasagittal approach in the right hemisphere (see Fig. $1 B$ ). Pallidal neurons were identified by their characteristic high-frequency, irregular baseline firing pattern and short duration action potentials (DeLong, 1971; Turner and Anderson, 1997). When one (or, infrequently, more than one) pallidal units were isolated by the recording electrode and the recording stability was determined to be acceptable based on online, realtime sorting of neuronal data (Tucker Davis Technologies), a short train $(<5 \mathrm{~s})$ of highfrequency DBS stimulation was delivered to train the artifact subtraction system. Stimulation was delivered using an isolated constant-current stimulator (Model 2100, A-M Systems) with symmetric biphasic pulses (60 $\mu$ s in duration) delivered at $150 \mathrm{~Hz}$ and 200 $\mu \mathrm{A}$. Neuronal data and behavioral event codes were then collected following a standard protocol of 20 behavioral trials performed without STN stimulation, followed immediately by 20 behavioral trials performed during STN DBS stimulation. This set of 40 total trials (mean duration $=213 \mathrm{~s}$ ) constituted one data "block." Ideally, we collected data continuously for 3 blocks; however, data collection was halted if unit isolation deteriorated.

Histology. After the last recording session, each monkey was tranquilized with a large dose of ketamine $(25 \mathrm{mg} / \mathrm{kg}$, i.m.) followed by a lethal dose of sodium pentobarbital $(40 \mathrm{mg} / \mathrm{kg}$, i.p.) before being perfused transcardially with saline followed by $10 \%$ formalin in phosphate buffer and then sucrose. The brains were blocked in place in the coronal plane, removed, cryoprotected with sucrose, and cut into 50 $\mu \mathrm{m}$ sections. Sections at $0.5 \mathrm{~mm}$ intervals were stained with cresyl violet for localization of microelectrode tracks and stimulating electrodes (see Fig. 1B). Because of a tissue processing accident, histology from the vicinity of the STN electrode was lost for Monkey B.

Offline analysis. The initial step of offline processing removed any residual stimulation artifacts that appeared in the continuous neuronal data as intermittent, high-frequency (150 $\mathrm{Hz}$ ) signals phase-locked to the times of stimulus delivery. This step was performed under investigator guidance to ensure that neuronal spiking data were not lost (e.g., due to artifactinduced amplifier saturation or spurious subtraction of antidromic-like action potentials). The neuronal data were then thresholded, and candidate action potentials were sorted into clusters in principal components space (Off-line Sorter, Plexon). Neurons were accepted for further analysis only if the unit's action potentials were of a consistent shape and could be separated reliably from the waveforms of other neurons as well as from background noise. Additionally, data files had to contain at least one complete "block" of data (20 successful trials off-stimulation, followed by 20 successful trials on-stimulation).

A neuronal record was subjected to further analysis if the neuron's spike activity was affected significantly by STN-DBS. We tested for effects of STN-DBS on a neuron's firing rate by constructing a peristimulus time histogram (PStH) from the last $30 \mathrm{~s}$ of stimulation averaged across all valid stimulation blocks (bin size $=0.2 \mathrm{~ms}, 35$ bins) (McCairn and Turner, 2009). A cell's PStH was then compared with a population of control histograms (PCtHs) constructed around "sham stimulation" time points (aligned at $6.67 \mathrm{~ms}$ intervals to correspond to $150 \mathrm{~Hz}$ ) applied to 30-s-long off-stimulation control periods. A neuron's "control" firing rate (mean across PCtHs) was subtracted so that both histogram types (PCtHs and PStH) reflected stimulation- (and sham-) induced changes from baseline firing rates. Increases and decreases in firing (i.e., above and below the baseline firing rate, respectively) were detected in the PStHs, and the areas of those deviations were converted to $z$-scores relative to the population of control deviation areas (i.e., to the areas of all deviations from baseline in all PCtHs for a neuron). The threshold for significance was adjusted to compensate for multiple comparisons $[\alpha=$ $0.01 /$ (mean number of deviations detected per PCtH)]. Effects of stimulation were categorized as "phasic" if the range of values in a $\mathrm{PStH}\left(\mathrm{PStH}_{\text {maximum }}-\mathrm{PStH}_{\text {minimum }}\right)$ exceeded the range found in PCtHs ( $t$ test; $\alpha=0.01$ ).

The degree to which a neuron's firing was "entrained" to the stimulation frequency was quantified as the area of deviation of the PStH from a flat distribution. Specifically, each neuron's PStH was normalized by the mean of the PStH, and the bin-by-bin deviation of the PStH from the mean was summed to produce a single value of relative entrainment (RE, 


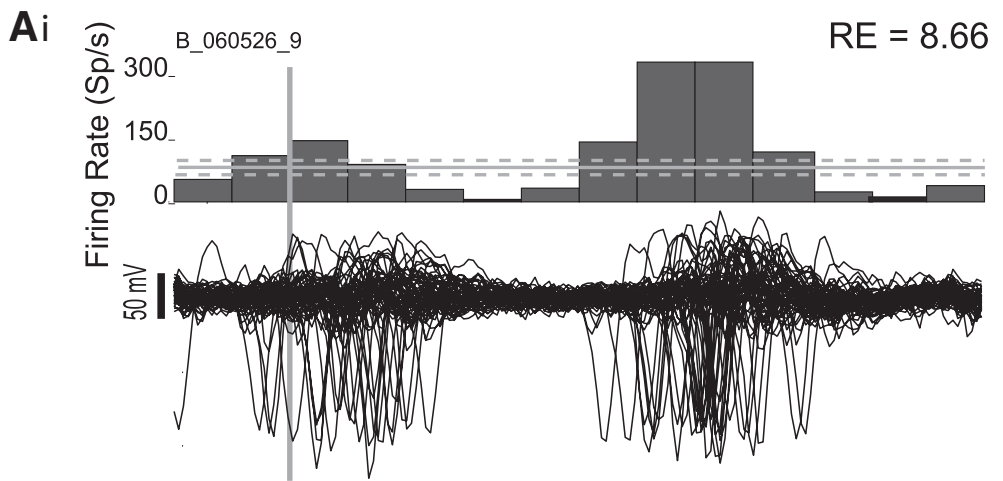

ii

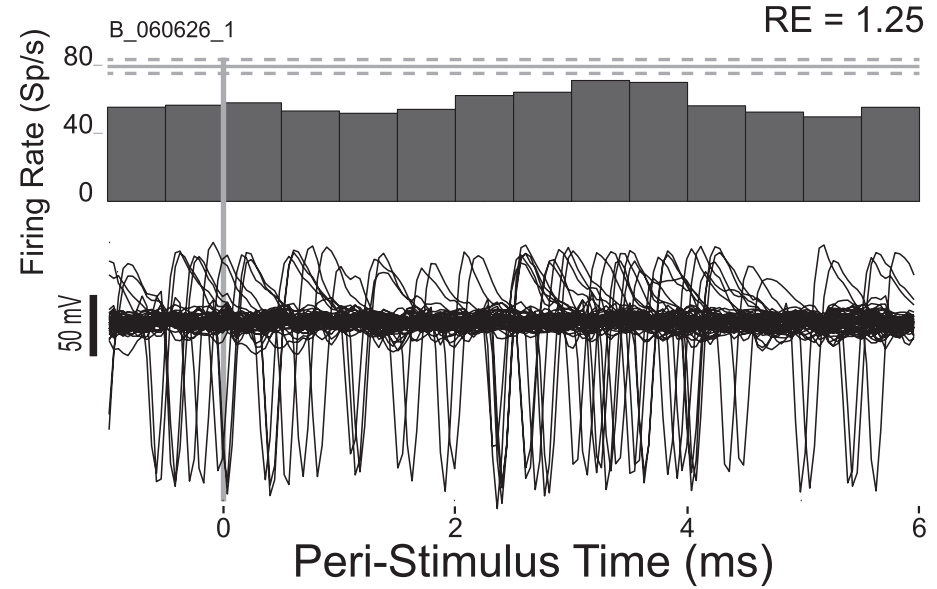

B

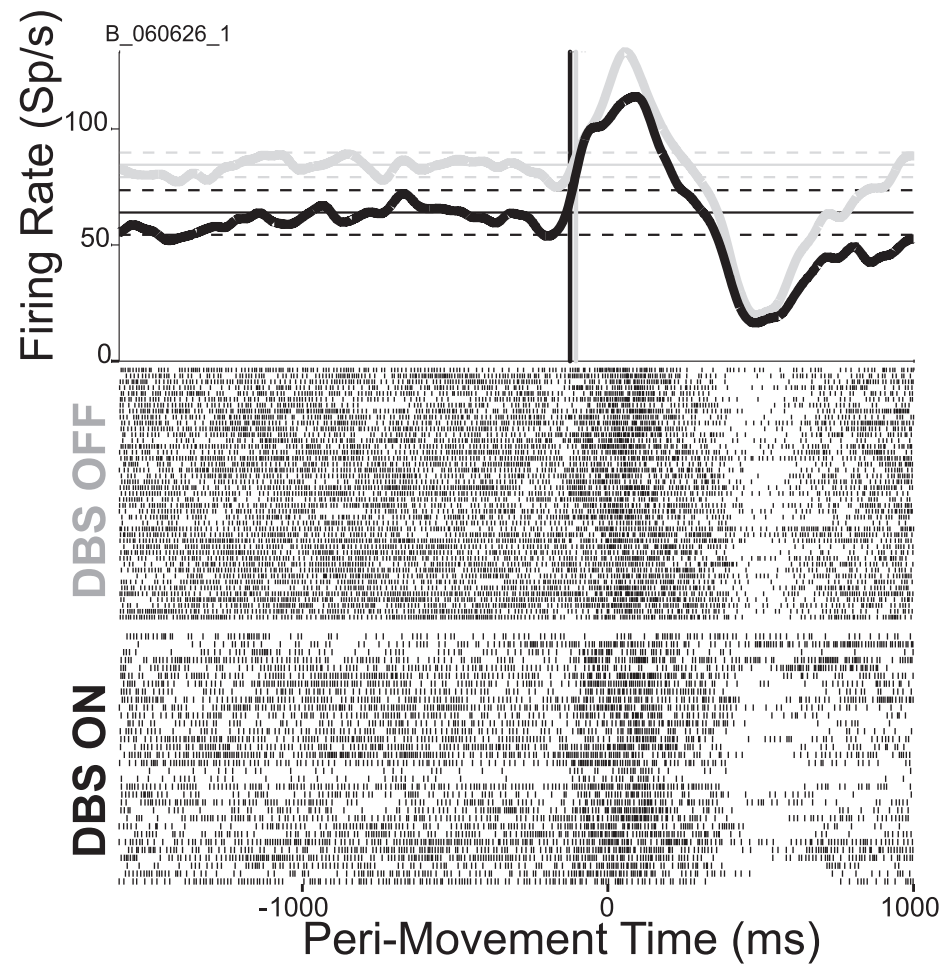

Figure 2. Exemplar effects of STN-DBS $(\boldsymbol{A})$ and movement $(\boldsymbol{B})$ on pallidal neuron activity. $\boldsymbol{A}$, Overlain raw microelectrode signals from 50 consecutiveSTN-DBS stimuli (vertical gray line). No shockartifactis evident due to effective operation of theartifact subtraction algorithm during data collection. Peristimulus histograms (above) illustrate phasic driving of a unit (i) and a tonic decrease in firing (ii). Unit $i$ is highly entrained to the stimulation frequency ( $\mathrm{RE}=8.66)$, whereas unit $i$ i is poorly entrained $(\mathrm{RE}=1.25)$. Horizontal solid lines indicate mean unit firing rate $( \pm 95 \% \mathrm{Cl}$ horizontal dashed lines) from the DBS-offcondition. B, Perimovementactivity of the same unitshown in Aii, aligned to theonset of movements (time 0) performed during the DBS-off (gray SDF and top rasters) and DBS-on (black SDF and bottom rasters) periods. Horizontal solid lines indicate mean control period fring rates ( $\pm 95 \%$ Cl horizontal dashed lines) for DBS-off and DBS-on periods. Vertical lines indicate onset times for significant $(p<$ 0.01) movement-related change in the SDF. Gray vertical line and black vertical line indicate DBS-off and DBS-on SDFs, respectively. arbitrary units). RE is termed relative entrainment because this measure is independent of the neuron's mean firing rate during stimulation. Conceptually, RE can be considered a measure of the degree to which a neuron's action potentials were time-locked to stimulation shocks. A high RE value indicates a high level of entrainment and a greater restriction of the times at which the cell spiked in the peristimulus interval, compared with stimulation effects with lower RE values.

Perimovement changes in firing rate were detected using an established method (Fig. 2B). Briefly, a mean spike density function (SDF; 25 $\mathrm{ms} \sigma$ Gaussian function convolved with a spike $\delta$-function) was constructed around the onset of all reach movements. (For all of the analyses performed here, data were combined across reaches to left and right targets.) Control values (mean and SD firing rate), taken from a $700 \mathrm{~ms}$ window that ended at the median time of cue onset, were used to test for significant changes in firing rate during the perimovement period (a $700 \mathrm{~ms}$ time window beginning immediately after the control period). A movement-related change in firing rate was defined as a significant deviation from the control mean rate that lasted at least $100 \mathrm{~ms}$ (Fig. $2 B$, solid vertical lines) ( $t$ test; one sample vs control period mean; omnibus $p<0.01$ after Bonferroni correction for multiple comparisons). The first significant time bin was taken as the time of onset of the perimovement change in firing. The magnitude of a perimovement change in firing was measured as the maximal deviation of an SDF from baseline firing expressed as a fraction of a cell's baseline firing rate. This approach detected and measured only the first (i.e., earliest-occurring) perimovement modulation in firing. Subsequent changes (e.g., the later decrease in Fig. 2B) were not analyzed.

To examine the degree to which STN-DBS altered the timing and form of pallidal movement-related activity, we compared histograms of a neuron's perimovement firing rates constructed separately from DBS-off and DBS-on periods. Histograms were used for this analysis, rather than SDFs, because each bin of a histogram provided an independent estimate of mean firing rate during a discrete time period relative to movement onset. In contrast, neighboring estimates in an SDF are not independent of each other because of the temporal blurring of spike information introduced by the Gaussian convolution. Each histogram consisted of 6025 -ms-wide bins that ranged from $0.5 \mathrm{~s}$ before movement onset to $1.0 \mathrm{~s}$ following movement onset. The degree to which a neuron's perimovement modulation in firing rate was consistent across stimulation conditions was measured using a Spearman correlation comparing firing rate values from the 60 bins of the DBS-off and DBS-on histograms. The correlation coefficient yielded by this analysis will be referred to as "off/on- $\rho$ " to distinguish this specific metric from the results from other correlation analyses.

Calculation of firing rate entropy. A previous study reported that DBS reduces the theoreti- 
cal information capacity of spontaneous neuronal activity, using as a measure the "entropy" of single-unit spike trains (i.e., entropy per spike) collected from animals at rest (Dorval et al., 2008). To relate our results to that study, we calculated the effects of DBS on neuronal entropy using the algorithm that is described in detail previously (Dorval, 2008, 2011; Dorval et al., 2008). Also following the methods used by Dorval et al. (2008), we excluded from this analysis any pallidal units that exhibited a very low $(<2 \mathrm{~Hz})$ mean firing rate during STN-DBS $(n=2)$.

In brief, a cell's spike train during the start position hold-period of all behavioral trials (2.6-4.8 s duration) was extracted and converted into separate series of interspike intervals (ISIs) for DBS-off and DBS-on periods. The ISIs were placed into logarithmic bins with the first bin, including the shortest observed ISI and the $K^{\text {th }}$ bin including the longest observed ISI (Dorval, 2008). The right-most edge of each ISI bin was defined as $I S I_{k}=I S I_{0} \times 10^{k / \kappa}$, where $k$ varied from 1 to $K$. $\kappa$ was defined as 20 (determined empirically by Dorval et al., 2008). Two, separate maximum likelihood entropy estimates ( $\mathrm{H}^{\mathrm{MLE}}$ ) (Dorval et al., 2008) were then calculated for each series of ISIs as follows:

$$
\begin{gathered}
H_{1 D}^{M L E}=-\sum_{a-1}^{K} P\left(I_{S}\right) \log _{2} P\left(I S I_{a}\right) \\
H_{2 D}^{M L E}=-\sum_{a-1}^{K} \sum_{b-1}^{K} P\left(I_{S}, I_{b} S I_{a}\right) \log _{2} P\left(I S I_{b} \mid I S I_{a}\right)
\end{gathered}
$$

where $I S I_{a}$ represents the $a^{\text {th }}$ ISI bin. $H_{1 D}^{M L E}$ and $H_{2 D}^{M L E}$ correspond to the estimates calculated via the assumption that the probability of each binned ISI is independent of the probability of all other ISIs occurring (1-dimensional), and the assumption that the probability of a binned ISI occurring is influenced by the immediately preceding binned ISI (2dimensional), respectively.

To overcome the potential for undersampling bias, entropy estimates in the first and second dimensions were extrapolated from subsets of the complete series of ISIs (Strong et al., 1998; Panzeri et al., 2007; Dorval et al., 2008). In other words, each series of ISIs was divided into two, then three, equally sized datasets. The $H_{1 D}^{M L E}$ and $H_{2 D}^{M L E}$ were calculated for each fractional dataset, yielding 12 total entropy estimates (one estimate obtained from the complete dataset, one estimate obtained from each onehalf dataset, and one estimate obtained from each one-third dataset, per dimension). A bias-corrected estimate was obtained for each dimension by plotting the mean of each dimensional estimate against the fraction of the dataset size, fitting the points to a quadratic function, and finding the value of the function at 0 (Dorval et al., 2008). Finally, we calculated the direct entropy estimate $\left(H_{D i r}\right)$ as the 0 -crossing of the linear fit of the dimensional estimates $\left(H_{\text {Dir }}=2 H_{2 D}-H_{1 D}\right)$. Cells that demonstrated significant changes in entropy with DBS application were identified via a bootstrapping method, in which the DBS-off and DBS-on series of ISIs were subsampled 1000 times, and $H_{D i r}$ was calculated for each sample, producing ${ }^{D B S-o n} H_{D i r}$ and ${ }^{D B S-o f f} H_{D i r}$. The change in entropy ( $\Delta$ Entropy per spike) was calculated as the difference between these two values. A cell was considered to have a significant change in entropy with DBS application if the $95 \%$ confidence interval of the mean of $\Delta$ Entropy did not overlap 0 .

Test for independent effects of task and stimulation. We then determined whether DBS and active movement affected neuronal firing rates independently (Bar-Gad and Turner, 2009). We reasoned that a DBSinduced degradation of movement-related signaling should appear as a significant interaction between the DBS- and movement-related modulations in firing rate. To test this, we constructed an empirical joint peristimulus time histogram (JPSTH) for each neuron, by computing separate perishock histograms $(0.5 \mathrm{~ms}$ bin size) for each $100 \mathrm{~ms}$ bin across the perimovement period ( -0.5 to $1 \mathrm{~s}$ relative to movement onset). The empirical JPSTH was regressed against two linear models: one containing the normalized peristimulus time histogram $\left(\mathrm{PStH}_{\mathrm{N}}\right)$ and normalized perimovement time histogram $\left(\mathrm{PMtH}_{\mathrm{N}}\right)$ as regressors (Independent Model) and one containing additionally an interaction term (computed as the normalized product of the $i$ th bin of the global perimovement histogram and the $j$ th bin of the global peri-DBS histogram) in addition to the regressors of the first model (Interaction Model) as follows:
Independent Model: JPSTH $H_{E m p}=\beta_{1} P S t H_{N}+\beta_{2} P M t H_{N}$

Independent Model:JPSTH $H_{E m p}=\beta_{1} P S t H_{N}+\beta_{2} P M t H_{N}$

$$
+\beta_{3}\left(P S t H_{N} * P M t H_{N}\right)
$$

The quality of the fit of each model to the empirical JPSTH was compared using the Akaike information criterion (AIC) (Burnham and Anderson, 2002):

$$
A I C_{\text {Model }}=2 k-2 \ln (L)
$$

Here, $k$ represents the number of model parameters and $L$, the likelihood, estimated from the residual sum of squares. The AIC value is an estimate of the information lost by applying a model to data. Given two models, the model that loses less information (the preferable model) will have the lower AIC value. For each recording, we determined whether the AIC difference between the two models was significant by bootstrapping the regressors (iterations $=1000$ ) of each model and calculating the singletailed $95 \%$ confidence interval of the mean of the resulting AIC difference distribution $\left(\mathrm{AIC}_{\text {Independent }}-\mathrm{AIC}_{\text {Interaction }}\right)$. If this confidence interval did not overlap 0 , the cell was classified as "Interaction Model preferring"; otherwise, the cell was classified as "Independent," indicating that the interaction of peristimulus and perimovement effects on firing rate did not contribute significantly to the cell's firing during stimulation and movement.

\section{Results \\ Database}

A total of 199 pallidal cells from the two animals met our criteria for signal quality, DBS-induced change in firing, and the minimum number of behavioral trials performed under DBS-off and DBS-on conditions. For these neurons, the mean duration of recording was $646.37 \mathrm{~s}$ (range: 146.00-1107.50 s) and STN-DBS was delivered during an average of $2.57 \pm 0.05$ blocks, each of which lasted $105.21 \pm 1.34 \mathrm{~s}$.

\section{Effects of STN-DBS}

\section{Behavioral}

As predicted by previous studies in normal rats (Aleksandrova et al., 2013; Creed et al., 2013; Kaminer et al., 2014), no gross motor abnormalities were observed during STN-DBS. Additionally, the monkeys' mean task performance (across all recording sessions) did not differ between DBS-off and DBS-on states (Monkey B: reaction time: $199.8 \pm 2.2 \mathrm{~ms}$ vs $176.3 \pm 2.2 \mathrm{~ms}$; movement time: $514.5 \pm 2.1 \mathrm{~ms}$ vs $534.1 \pm 2.1 \mathrm{~ms}$; Monkey D: reaction time: $365.1 \pm 3.6 \mathrm{~ms}$ vs $355.4 \pm 4.2 \mathrm{~ms}$; movement time: $219.32 .0 \mathrm{vs}$ $222.2 \pm 3.0 \mathrm{~ms}$, DBS-off and DBS-on, respectively, $p>0.05$ for all comparisons, $t$ test).

\section{Neuronal}

Consistent with previous reports (Hashimoto et al., 2003; Moran et al., 2011), the effects of STN-DBS on pallidal activity varied considerably between neurons, including both phasic and tonic increases and decreases in firing rate (Table 1). In the example shown in Figure $2 A i$, STN-DBS caused short-latency $(\sim 1 \mathrm{~ms})$ and longer-latency $(\sim 4 \mathrm{~ms})$ phasic increases in firing probability (compared with the cell's mean firing rate without STN-DBS, horizontal solid line) bracketed by reductions in firing probability. This neuron demonstrated a high degree of entrainment to the stimulation $(\mathrm{RE}=8.66$; population range: $0.33-25.25)$. Action potentials were easily discriminable throughout the peristimulus interval, even when the action potential overlapped the time of stimulus delivery (vertical solid line, time 0 ), reflecting effective operation of the artifact subtraction algorithm. As with 
Table 1. Pallidal effects of STN-DBS ${ }^{a}$

\begin{tabular}{|c|c|c|c|c|c|c|}
\hline & \multirow{2}{*}{$\begin{array}{l}\text { Total cells } \\
\text { studied }\end{array}$} & $\begin{array}{l}\text { Firing rate } \\
\text { increase }\end{array}$ & \multicolumn{2}{|c|}{$\begin{array}{l}\text { Firing rate } \\
\text { decrease }\end{array}$} & \multirow{2}{*}{$\begin{array}{l}\text { Antidromic- } \\
\text { like activation }\end{array}$} & \multirow{2}{*}{$\begin{array}{l}\text { Total cells responding } \\
\text { to stimulation }\end{array}$} \\
\hline & & Phasic Tonic & Phasic & Tonic & & \\
\hline Monkey B & 128 & 49 (38) 0 & $70(55)$ & $13(10)$ & $12(9)$ & $110(86)$ \\
\hline Monkey D & 104 & 46 (44) 1 (1) & $71(68)$ & $3(3)$ & $10(10)$ & $89(86)$ \\
\hline Total & 232 & $95(41) 1(0.4)$ & $141(61)$ & $16(7)$ & $22(9)$ & $199(86)$ \\
\hline
\end{tabular}

${ }^{a}$ Values are $n$ (\%). For description of detection of significance, see Methods. The numbers sum to $>100 \%$ because some cells showed phasic increases and decreases in firing during STN-DBS. There was no significant difference observed between the populations of the two animals $\left(\chi^{2}=6.93, p>0.05\right)$.

Table 2. GPe and GPi population response to STN-DBS ${ }^{a}$

\begin{tabular}{|c|c|c|c|c|c|c|c|}
\hline & \multirow{2}{*}{$\begin{array}{l}\text { Total cells } \\
\text { studied }\end{array}$} & \multicolumn{2}{|c|}{$\begin{array}{l}\text { Firing rate } \\
\text { increase }\end{array}$} & \multicolumn{2}{|c|}{$\begin{array}{l}\text { Firing rate } \\
\text { decrease }\end{array}$} & \multirow{2}{*}{$\begin{array}{l}\text { Antidromic-like } \\
\text { activation }\end{array}$} & \multirow{2}{*}{$\begin{array}{l}\text { Total cells responding } \\
\text { to stimulation }\end{array}$} \\
\hline & & Phasic & Tonic & Phasic & Tonic & & \\
\hline GPe & 141 & $50(35)$ & $1(0.7)$ & $80(57)$ & $12(9)$ & $14(10)$ & $115(82)$ \\
\hline GPi & 91 & $44(48)$ & 0 & $59(65)$ & $3(3)$ & $8(9)$ & $80(88)$ \\
\hline
\end{tabular}

${ }^{a}$ Values aren (\%). No significant difference was observed in the population responses of the two segments of the GP.

Table 3. Significant perimovement modulations off and on STN-DBS ${ }^{a}$

\begin{tabular}{llccc}
\hline & $\begin{array}{l}\text { DBS-off } \\
\text { only }\end{array}$ & $\begin{array}{l}\text { DBS-on } \\
\text { only }\end{array}$ & $\begin{array}{l}\text { Both DBS-off } \\
\text { and DBS-on }\end{array}$ & $\begin{array}{l}\text { Any significant perimovement modulation/ } \\
\text { stimulation responsive }\end{array}$ \\
\hline Monkey B & $17(15)$ & $8(7)$ & $69(63)$ & $94 / 111(85)$ \\
Monkey D & $10(11)$ & $7(8)$ & $65(73)$ & $\begin{array}{c}82 / 89(92) \\
\text { Total }\end{array}$ \\
\hline
\end{tabular}

${ }^{a}$ Values are $n$ (\% of stimulation responsive cells). For description of detection of significant perimovement modulations in firing rate, see Methods.

previous studies (Hayashi et al., 2003; Moran and Bar-Gad, 2010), phasic increases and decreases in firing rate like those shown in Figure $2 \mathrm{Ai}$ constituted a large fraction of the effects of STN-DBS on pallidal neurons (182 of 199, 91\% of cells significantly responding to stimulation). In smaller fractions of cells, STN-DBS induced a sustained decrease (16 of $199,8 \%$ ) or increase ( 1 of 199, 0.5\%) in firing. For the example shown in Figure $2 \mathrm{Aii}$, the firing rate was depressed for most the peristimulus interval (from $-1 \mathrm{~ms}$ to $\sim 3 \mathrm{~ms}$ and from $\sim 4$ to $6 \mathrm{~ms}$ ) relative to that during the DBS-off condition (horizontal solid line). In contrast to the cell shown in Figure $2 A i$, this neuron was not highly entrained to the stimulation frequency, as indicated by a low RE value (1.25). In 22 neurons, STN-DBS evoked an antidromic-like activation in which spikes appeared at a latency that was short $(1-3 \mathrm{~ms})$ and fixed $(<0.5 \mathrm{~ms}$ jitter) relative to stimulus delivery, with a relatively high fidelity (mean $25 \pm 3 \%$ of shocks evoked spikes). As observed previously (Hashimoto et al., 2003; Moran et al., 2011), the effects of STN-DBS on pallidal activity were indistinguishable for neurons located in the external and internal segments of the GP $\left(\chi^{2}=4.89, p>0.05, \chi^{2}\right.$ test of homogeneity) (Table 2). Therefore, all subsequent analyses were performed on the general population of pallidal neurons.

\section{Movement-related activity equally prevalent on and off DBS} The animals performed the reaching task throughout the DBSoff and DBS-on data collection periods (mean 63.05 \pm 1.52 and $46.72 \pm 1.18$ trials performed during DBS-off and DBS-on periods, respectively). As expected, a large fraction (161 of 199, 81\%) of the pallidal population demonstrated significant perimovement modulations in firing rate in the DBS-off state (Table 3). Figure $2 B$ (gray trace) shows an example in which a pallidal cell's firing rate increased beginning (vertical gray line) immediately before the time of movement onset (time 0). In the DBS-off state, perimovement increases in firing like the one shown in Figure $2 B$ were found in 115 of the 199 pallidal neurons (58\%). Perimovement decreases in firing rate were found in 46 pallidal cells $(23 \%$ of the STN-DBS responsive population).

Most pallidal neurons (149 of 199, 75\%) had significant perimovement alterations in firing rate during STN-DBS. Such an effect is illustrated in Figure $2 B$ (black trace). Although the baseline firing rate of this cell decreased significantly during STNDBS (Fig. 2B, horizontal solid lines; by $\sim 30 \mathrm{~Hz} ; p \ll 0.001, t$ test), the cell's modulation in firing rate around the time of movement onset, as well as the timing of that change (vertical black line), was highly similar under DBS-off and DBS-on states. The overall prevalence of perimovement modulations in firing rate did not differ between DBS-off and DBS-on states $\left(\chi^{2}=0.39\right.$, $p>0.05$; Table 3$)$. Furthermore, the relative prevalence of perimovement decreases and increases in firing did not differ significantly between DBS-off and DBS-on states (respectively, 23\% and $31 \%$ of neurons showed decreases and, $58 \%$ and $46 \%$ of neurons showed increases; all $\left.\chi^{2}=2.47, p>0.05\right)$. Notably, in a subpopulation of 15 neurons $(8.0 \%)$, perimovement modulations appeared only during STN-DBS (Table 3). A complete loss of perimovement activity during STN-DBS was observed in only 27 neurons (14\%; Table 3; for one example, see Fig. 3B).

Although perimovement modulations in firing did not differ in latency between DBS-off and DBS-on conditions $(-100.84 \pm$ $8.72 \mathrm{~ms}$ and $-91.4 \pm 12.97 \mathrm{~ms}$, respectively; $t$-value $=-0.57$, $p>0.05)$, the magnitude of movement-related changes increased with stimulation. Decreases in firing amounted to a mean change from baseline of 19\% ( \pm 3 SEM) and 32\% ( \pm 3$)$ for DBS-off and DBS-on conditions, respectively $(t$-value $=3.47, p<0.001)$. Although perimovement increases were also larger in the DBS-on state (mean $78 \pm 26 \%$ compared with $58 \pm 12 \%$ for DBS-off), this change did not reach significance $(t$-value $=0.82, p>0.05)$.

\section{Preservation of the form and timing of movement- related activity}

In addition to the observation that most pallidal neurons showed movement-related activity during both DBS-off and DBS-on conditions (Table 3), inspection suggested that the form and timing of the movement-related changes were often similar between conditions (e.g., Fig. 2B). To investigate that possibility quantitatively, we compared the binned, perimovement firing rates (25 ms bins) of all GP cells that demonstrated both a significant effect of STN-DBS and any significant perimovement modulation in firing rate under DBS-off or DBS-on states $(n=176)$. Figure $3 A$, $B$ shows perimovement histograms for two example neurons: one in which the movement-related modulation was preserved during DBS (Fig. 3A) and another in which the movementrelated modulation disappeared (Fig. $3 B$ ). We quantified the similarity of a cell's perimovement modulations between DBS-off and DBS-on conditions using Spearman correlations of the bin-by-bin measures of firing rate. As expected, DBS-off and DBS-on firing rates were highly correlated for the first example neuron (Fig. 3C; off/ on- $\rho=0.62 ; p \ll 0.001$ ) and not correlated for the second (Fig. 3D; off/on- $\rho=0.03 ; p>0.05)$.

Across the population as a whole, the majority of pallidal units (116 of $176,66 \%)$ demonstrated a significant $(p<0.05)$ positive correlation in perimovement firing rates from the DBS-off and DBS-on states (Fig. 3E, black bars; mean off/on- $\rho=0.39$ ), which is consistent with the view that the general form and timing of changes in activity around the time of movement onset were preserved during STN-DBS. Among the 60 cells in which off/ on- $\rho$ was not significant and positive (Fig. $3 E$, white and gray 
bars), the majority (47 of $60,78 \%$ ) still showed significant perimovement discharge during DBS.

When DBS did alter a cell's movement-related activity, the degree of alteration correlated approximately with the DBS-induced RE of spiking (Fig. $3 F$ ). In other words, the more the spiking of a pallidal neuron was time-locked to the delivery of individual stimulus pulses (see Materials and Methods), the more stimulation tended to reduce the off/on- $\rho$ (Fig. $3 F$; Spearman $\rho=-0.38, p<0.001$ ). Although this relationship was significant, between-cell differences in entrainment explained only $13 \%$ of the variance in off/ on- $\rho$ (least-squares linear fit). The majority of cells demonstrated a significant change in resting entropy with STN-DBS (152 of 176, 86\%; Fig. 3G, +; for estimation of significance, see Materials and Methods), and there was a modest, yet significant, correlation between the effects of DBS on firing entropy ( $\triangle$ Entropy, expressed as a percentage of DBS-off entropy) and its effect on perimovement activity (as measured by off/on- $\rho$; Fig. $3 G$; Spearman $\rho=0.22, p<0.01$ ). Similar to the relationship between degree of entrainment and off/on- $\rho, \Delta$ Entropy accounted for only a small (8\%) portion of the variance in off/on- $\rho$ (least-squares linear fit). In agreement with previous reports (Dorval et al., 2008; Dorval and Grill, 2014), population-level resting entropy decreased significantly with STNDBS (4.83 \pm 0.04 bits/spike; $4.53 \pm 0.09$ bits/spike, DBS-off and DBS-on, respectively, $t$-value $=-2.98, p<0.05, t$ test). The DBS-induced changes in baseline firing rate $(\Delta \mathrm{FR})$ ranged from $-96 \%$ to $332 \%$ (expressed as a fraction of the cell's firing rate off DBS; significant in 137 of 176 cells, $78 \%$, $t$ test; Figure $3 H,+$ ). However, off/on- $\rho$ did not correlate with the cell's $\Delta$ FR $(\rho=-0.14 ; p>0.05)$.

To summarize, attenuation or alteration of a pallidal neuron's movementrelated signaling was more likely when DBS strongly entrained the timing of the neuron's spiking and decreased the cell's resting entropy but was unrelated to effects of DBS on mean firing rate.

\section{Joint effects of movement and STN- DBS on pallidal activity}

The observation that movement-related modulations in firing rate were often preserved during DBS despite strong DBSinduced changes in firing rate suggested that the effects of movement and DBS on pallidal activity were often independent and additive. To test that idea directly, we
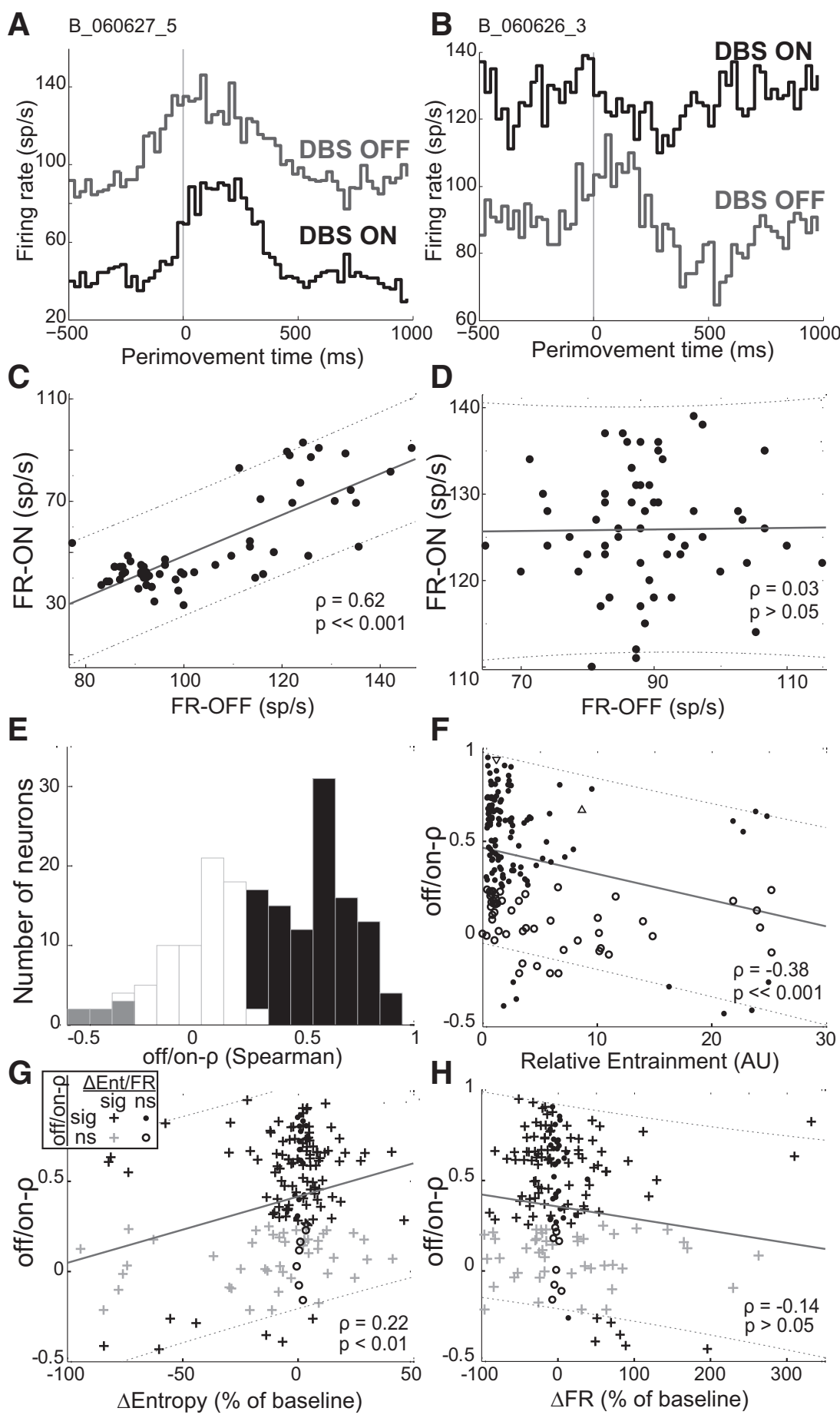

Figure 3. Preservation of perimovement firing pattern with STN-DBS. $\boldsymbol{A}$, Perimovement histograms of a unit that showed strong preservation of DBS-offfiring pattern (increase in firing rate $\sim 20$ ms before movement onset, gray trace), during DBS-on (black trace). Both histograms are aligned to movement onset (time 0 ). $\boldsymbol{B}$, Perimovement histograms, constructed as in $\boldsymbol{A}$, of exemplar pallidal cell demonstrating loss of significant perimovement activity during DBS-on. $\boldsymbol{C}$, Scatter plot of bin-by-bin firing rates from the DBS-on condition ( $\boldsymbol{A}$, black trace) plotted versus those from the DBS-off condition ( $A$, gray trace). Perimovement firing rates of this cell in the DBS-off and DBS-on state were highly correlated (results from " off/on- $\rho$ " Spearman correlation inset and solid line) indicating a preservation of the timing and shape of perimovement activity throughout stimulation. $\boldsymbol{D}$, Scatter plot (following the conventions of $\boldsymbol{C}$ ) of the neuron shown in $\boldsymbol{B}$. The perimovement firing rates of this neuron (in the DBS-off and DBS-on state) were not significantly correlated, indicating a loss of perimovement activity during stimulation. $\boldsymbol{E}$, Population summary of the off/on- $\rho$ values reflecting the degree to which DBS-off perimovement activity was preserved during STN-DBS (116 of $176,66 \%$ black bars; gray bars: significant negative off/on- $\rho$ values). $\boldsymbol{F}$, Strong entrainment of spiking to DBS reduced the preservation of movement-related activity (off/on- $\rho$ ). Filled circles represent significant off/on- $\rho$ value (as reported in $E$ ). Open circles represent nonsignificant off/on- $\rho$ value. $\Delta$ indicates the neuron shown in Fig. $2 A i$. $\nabla$ indicates the neuron shown in Fig. 2Aii. G, $\boldsymbol{H}$, The degree to which movement-related activity was preserved during DBS (off/on- $\rho$ ) correlated with the effects of DBS on resting entropy $(\Delta$ Entropy) $(\boldsymbol{G})$ but not baseline firing rate $(\Delta F R)(\boldsymbol{H}) . \boldsymbol{G}$, Inset, legend for the symbol shapes and colors used in $\boldsymbol{G}$ and $\boldsymbol{H}$. sig, Significant; ns, nonsignificant. Dashed lines indicate $95 \%$ confidence interval of correlation. 
A

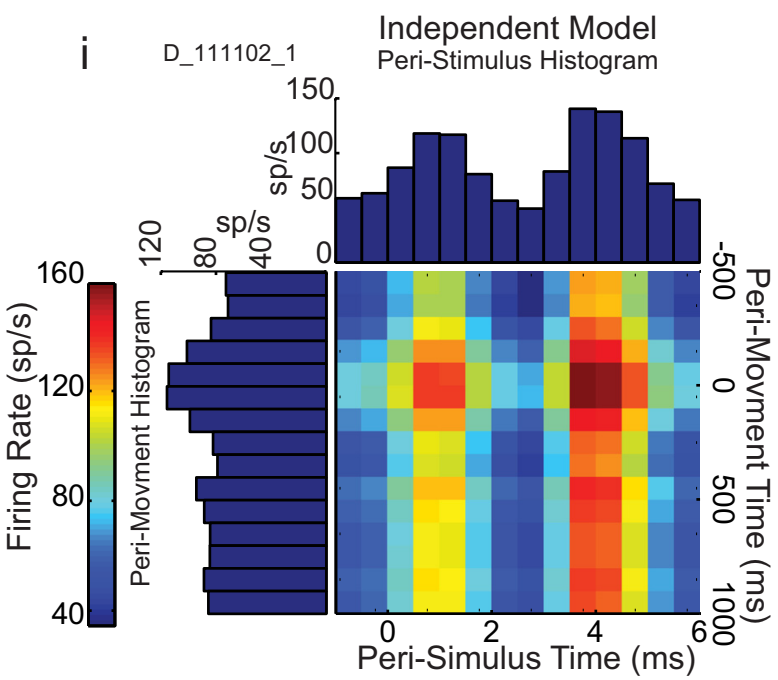

ii

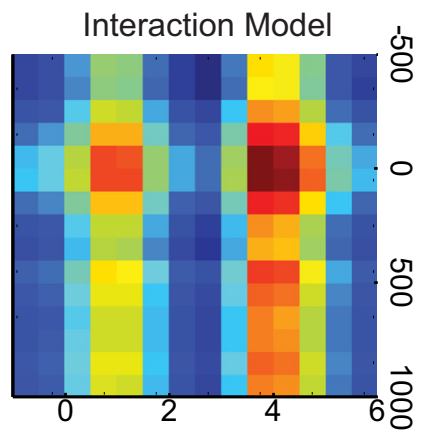

iii

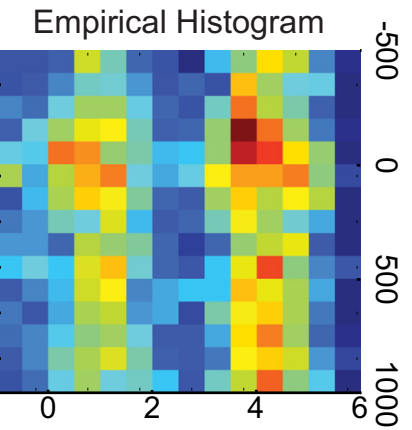

B

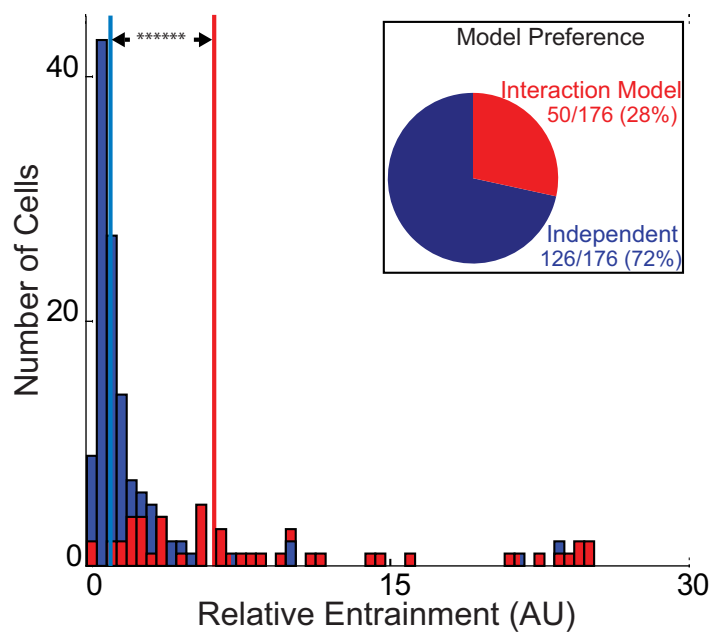

fit each cell's observed firing rate, in joint perimovement and peristimulation time, with two regression models: one in which a cell's firing rate, at any point in time, is determined independently by the mean peristimulus and perimovement firing rates (Fig. $4 A i$, Independent Model), and one in which the effects of DBS and movement also interact (Fig. 4Aii, Interaction Model). Such an interaction can be conceptualized as points in time when a cell's firing was driven (or inhibited) to such a degree that additional firing rate increases (or decreases), representing movement-related modulations in firing, were physiologically impossible. If the effects of stimulation and movement on pallidal activity are orthogonal and additive, then the Interaction Model will not provide a better fit to the empirically observed joint histogram (produced by binning the cell's spikes in perimovement and peristimulus times; Fig. 4Aiii, Empirical Histogram). In the results from one cell illustrated in Figure $4 A$, Independent and Interaction Models fit the empirical histogram equally well (i.e., the AIC values for the two fits were not significantly different), suggesting that DBS and movement had independent, additive effects on the cell's firing rate (AIC difference $=0.65, p<$ 0.05 ; for description of AIC calculation, see Materials and Methods). Across the population of pallidal units $(n=176)$, Independent effects of stimulation and movement were found in 126 cells (72\%, Fig. $4 B$, inset). A significant interaction between the effects of stimulation and movement was more likely when a cell was strongly entrained to the stimulus pulse, as evidenced by a higher median RE for Interaction Model preferring cells compared with that of Independent cells [Figure $4 B$, vertical red line vs vertical blue line, median ( \pm MAD) RE: 6.29 (3.86) vs 1.16 (0.48), respectively]. As a population, the RE values of Interaction Model preferring cells differed significantly from those of Independent cells (two-sample Kolmogorov-Smirnov test, $p \ll 0.001$ ).

\section{Discussion}

The present results address a prediction of the informational lesion hypothesis, which states that, during STN-DBS, spiking activity in efferent targets of the STN is entrained so closely to the high-frequency stimuli of DBS that it no longer encodes other information, creating a "virtual lesion" (Grill et al., 2004; Garcia et al., 2005; Dorval et al., 2008, 2010; Guo et al., 2008; McConnell et al., 2012; Rubin et al., 2012; Agnesi et al., 2013). Straightforward conceptions of the informational lesion hypothesis predict that high-frequency stimulation also blocks the transmission of task-related modulations in firing rate. We tested this second prediction by recording from the GP of monkeys while they performed a reaction time reaching task both off and on STN-DBS.

\footnotetext{
Figure 4. Movement and stimulation are orthogonal contributors to GP cell firing. Ai, Construction of Independent Model joint histogram from peristimulus and perimovement, 1-dimensional histograms. The peristimulus and perimovement histograms were derived from the recordings of a pallidal neuron. The binned firing rates of these 1-dimensional histograms were normalized and multiplied by the regression coefficients produced using the Independent Model to produce the 2-dimensional histogram. Aii, The 2-dimensional histogram, for the same cell shown in $\boldsymbol{A i}$, as predicted by the Interaction Model. Aiii, An empirical joint histogram produced for the same neuron by binning the firing rate of the cell relative to peristimulus and perimovement times. $\boldsymbol{B}$, Distribution of Interaction Model Preferring cells and Independent cells, in terms of RE. Inset, Model preference as percentage of cells tested. Red bars represent cells that were modeled significantly better by Interaction Model as determined by the AIC value. Blue bars represent Independent cells. Vertical red line indicates median RE value for cells that were modeled significantly better by Interaction Model. Vertical blue line indicates median RE value for Independent cells.
} 
To our knowledge, ours is the first study to examine the effects of STN-DBS on pallidal discharge during active movement.

Despite alterations to resting firing rate and entropy, STNDBS did not block the occurrence of perimovement modulations in firing rate in a majority of DBS-responsive GP cells $(75 \%$; Table 3). Furthermore, the form and timing of perimovement modulations in firing were preserved during STN-DBS in the majority of GP cells (66\%; Fig. 3E, black). It should be noted that this latter analysis addressed the preservation of specific perimovement modulations in firing during STN-DBS; many of the cells that did not demonstrate significant preservation still possessed significant perimovement modulations during DBS. STNDBS completely abolished perimovement activity in only a small fraction of neurons (14\%; Table 3; for one example, see Fig. $3 B$ ). Thus, the method that we used to quantify the preservation of movement-related activity was stringent and may have overestimated the propensity for STN-DBS to degrade pallidal taskrelated activity.

A recent study by Angesi et al. (2013) reported that DBS in the pallidum often reduced a pallidal neuron's sensitivity to one or another specific parameter of proprioceptive stimulation, a result that could be taken as support for the informational lesion hypothesis. Our results and those of Angesi et al. (2013) are compatible, however. First, like us, Agnesi et al. (2013) found that DBS did not block a neuron's general ability to transmit taskrelated information in the majority of pallidal neurons studied (in 149 of 199 [75\%] pallidal cell here and in 10 of 16 cells [62\%] in Agnesi et al., 2013). Second, the two studies differed significantly both in experimental approach (e.g., stimulation in the STN here vs in the GPi for Agnesi et al., 2013) and in analysis used (e.g., correlation analysis here vs generalized linear model in Agnesi et al., 2013). Third, neuronal signaling related to active movement (studied here) and that reflecting proprioceptive afference (like those studied by Agnesi et al., 2013) may be influenced in different ways by the circuit-level effects of DBS. Related to that point, we saw no DBS-induced changes in gross motor performance in our neurologically normal animals, whereas Agnesi et al. (2013) observed a DBS-induced reduction in muscle rigidity in animals that were mildly parkinsonian or dystonic. Finally, both studies found a fraction of pallidal neurons (albeit, a minority here) that did show a significant loss or alteration of movement-related activity during STN-DBS. A loss of perimovement activity in $14 \%$ of pallidal cells (Table 3 ) and altered movement-related activity in $44 \%$ of cells (Fig. $3 E$ ) might have impaired classes of behavior that our simple reaching task did not assay (e.g., response inhibition or switching) (Baunez et al., 1995; Ray et al., 2009; Hershey et al., 2010; Jahanshahi et al., 2014). It should be noted that the absence of overt behavioral effects of STN stimulation was not unexpected. Of the many previous studies of STN-DBS, only one (Beurrier et al., 1997) reported hyperkinetic symptoms, and then, those symptoms were elicited only with high currents $(800 \mu \mathrm{A}$, four times our maximum stimulation current).

It is important to recognize several limitations to the present results. First, we recorded from neurologically normal animals. Several lines of evidence suggest this is not a major drawback. The effects of STN-DBS on pallidal firing that we observed (Table 1) were closely similar to those reported during therapeutic STNDBS in parkinsonian monkeys by Hashimoto et al. (2003) and Moran et al. (2011). The decrease in resting pallidal entropy with STN-DBS that we report ( $0.3 \mathrm{bit} /$ spike difference) is remarkably close to the decrease that Dorval et al. (2008) reported for the parkinsonian primate. Additionally, studies in vitro (Garcia et al.,
2003) and in vivo in rats (Tai et al., 2003) suggest that cellular responses within the BG to STN-DBS are independent of an animal's clinical status. Furthermore, performing the study in parkinsonian animals would introduce a significant confound. Parkinsonism is associated with a marked loss of specificity in the responses of single units in the pallidum (Filion et al., 1988, 1989; Boraud et al., 2000). Thus, in parkinsonian animals, a DBS-induced reduction in taskrelated responsiveness could be interpreted equally well as evidence for a degradation of normal task-related activity (relevant to the current question) or evidence for a DBS-induced restoration of functional specificity.

Second, it is possible that STN-DBS induced an informational lesion near the site of stimulation in the STN, but that that effect was not manifested strongly in the activity of GP neurons. Although we cannot rule out this possibility, we believe it is unlikely. Several lines of evidence indicate that STN activity is an important contributor to the resting and task-related activity of neurons in both pallidal segments (Hamada and DeLong, 1992; Wichmann et al., 1994; Nambu et al., 2000; Nambu et al., 2002; Tachibana et al., 2008). The idea that DBS blocked the flow of important task-related information through the STN is incompatible with the present results (a relative preservation of task-related activity during STN-DBS). It is also worth noting that most accounts of the informational lesion hypothesis (Grill et al., 2004; Garcia et al., 2005; Dorval et al., 2008, 2010; Guo et al., 2008; McConnell et al., 2012; Rubin et al., 2012; Agnesi et al., 2013) do not restrict the hypothesized lesion-like effect to an anatomic region immediately surrounding the site of stimulation, but rather propose a blockade of information transmission through the whole affected BG circuit, including the pallidum.

Third, the effects of stimulation on nearby somata and fiber tracts are influenced by the geometry of the electrode and the stimulation parameters used (Miocinovic et al., 2006). Although the frequency and amplitude of stimulation used in our study were similar to those found to be therapeutic in previous studies with parkinsonian nonhuman primates (Hashimoto et al., 2003; Meissner et al., 2005; Moran et al., 2011, 2012), we cannot confirm that the stimulation delivered would be therapeutic to a parkinsonian animal. Our electrodes did not reproduce the exact shape of the stimulating electrodes used clinically, and we used symmetric biphasic stimulus pulses, whereas clinical stimulators typically use asymmetric biphasic pulses. Because of these differences, our results may not extrapolate perfectly to the clinical setting.

Fourth, our results show that modulations in pallidal firing rate around the time of movement initiation are largely preserved during STN-DBS, but whether the encoding of specific taskparameters (such as directionality, reward size, and kinematics) (Turner and Anderson, 1997; Pasquereau et al., 2007) is preserved during STN-DBS remains to be seen. Finally, our study focused only on the preservation of movement-related activity in the spiking activity of pallidal somata. Modeling studies have shown that it is possible for stimulation to have different effects on a neuron's soma and on the neuron's axonal projections (Miocinovic et al., 2006). Because of the placement of the stimulating electrode contacts in the dorsal STN, close to the path of pallido-thalamic fibers in the Field of Forel (Hamani et al., 2004; Miocinovic et al., 2006; Wodarg et al., 2012), it may be possible for STN-DBS to disrupt the propagation of motor-related activity along the pallido-thalamic pathway without necessarily disrupting the encoding of movement at the somatic level within the pallidum. Future recording studies in the thalamus are needed to address this possibility. 
The degree to which STN-DBS degraded or altered movement-related activity did not correlate with the effects of STN-DBS on baseline firing rates (Fig. $3 H$ ) and was modestly correlated with DBS-induced changes in entrainment (Fig. $3 F$ ) and entropy (Fig. $3 G$ ). This observation suggests that most pallidal neurons were able to encode task-related information independent of the presence of STN-DBS induced changes in firing. We tested this idea directly by comparing a neuron's empirical joint perimovement/peristimulation histogram (Fig. 4Aiii) to two models: an Independent Model, which models firing rate as the additive effects of movement and stimulation (Fig. 4Ai); and an Interaction Model, which includes an interaction between movement and stimulation (Fig. 4Aii). The Interaction model did not improve the fit for a large fraction of the pallidal cells (72\%; Fig. 4B). The more DBS entrained a cell's firing, the greater the chance of a significant interaction (28\%; Fig. $4 B$, red bars). This relationship suggests that DBS degraded a cell's movementrelated discharge when the cell's firing was driven or inhibited to physiologic extremes. This interpretation is reinforced by the result shown in Figure 3F: a cell that is highly entrained to the stimulus pulse is less likely to preserve its DBS-off perimovement changes in firing rate. However, the majority of pallidal cells were not entrained to such a degree. Therefore, in most pallidal cells, instantaneous firing rate during contemporaneous movement and STN-DBS was well explained by two independent factors: time relative to movement onset and time relative to stimulus delivery.

The informational lesion hypothesis predicts that an entrainment of spiking to STN-DBS blocks the ability of pallidal neurons to modulate firing rates in response to other synaptic inputs. Inconsistent with that prediction, our results indicate that the majority of pallidal cells exhibit alterations in firing rate around movement onset that are similar in the DBS-off and DBS-on conditions, suggesting a similar responsiveness to synaptic input whether or not DBS is present. However, we also show that, as entrainment increases (on a millisecond timescale), and DBSinduced entropy decreases, the cell's ability to maintain DBS-off perimovement activity during STN-DBS decreases (Fig. $3 F$ and $3 G$, respectively). Thus, although a high degree of DBS-induced entrainment is capable of blocking the encoding of movementrelated information, the majority of cells in GP are only loosely entrained to the stimulation, a conclusion also supported by previous results (Hashimoto et al., 2003; Garcia et al., 2005; Reese et al., 2011; Agnesi et al., 2013; Cleary et al., 2013).

It should be noted that the relationship between relief from parkinsonian signs and pallidal entrainment to stimulation is not known. It is possible that therapeutic effect requires higher levels of entrainment than those induced here and, as a correlate (e.g., Fig. $3 F$ ), a greater degradation of task-related signaling. As noted above, however, previous studies (Hashimoto et al., 2003; Meissner et al., 2005; Moran et al., 2011, 2012) have reported significant antiparkinsonian effects from STN stimulation using frequency, current, electrode design, and pulse width and shape similar to those used here. The degree of pallidal population entrainment in those studies, although not quantified, also appears to be similar to what was observed here (Hashimoto et al., 2003, their Fig. 5). Thus, the available data suggest that high levels of pallidal entrainment are not required for symptom relief. Additional research is needed to determine the relationship between the degrees of entrainment and the therapeutic effects of STN-DBS.

In conclusion, we have observed that pallidal movementrelated discharge is largely preserved during stimulation. This result suggests that, in the parkinsonian state, DBS acts not as an informational lesion, but as an "information filter" (Rosenbaum et al., 2014) or a desynchronizing force (Wilson et al., 2011). We speculate that DBS may permit the transmission of task-related information through the BG while blocking the transmission of some of the resting pathologic firing characteristics of PD, such as low-frequency oscillations in the STN (Bergman et al., 1994; Levy et al., 2002; Soares et al., 2004; Meissner et al., 2005; Kühn et al., 2008; Moran et al., 2008; McConnell et al., 2012) and GP (Wichmann et al., 1994, 1999; Raz et al., 2000; Brown et al., 2004; McCairn and Turner, 2009). A filter or desynchronizing effect of DBS (Wilson et al., 2011; Rosenbaum et al., 2014) could explain the divergent motor (Slavin et al., 2004; Alvarez et al., 2005; Merello et al., 2006; Baraduc et al., 2013) and cognitive (Brown et al., 2003; Carbon and Eidelberg, 2006; Obeso et al., 2009) effects that follow lesions of the BG versus stimulation of the same structures. Our results suggest that DBS has a distinct advantage over ablative therapies (e.g., pallidotomy) in that the contributions of the BG to the control of behavior (instantiated as task-related modulations in discharge) appear to be largely preserved during DBS.

\section{References}

Agnesi F, Connolly AT, Baker KB, Vitek JL, Johnson MD (2013) Deep brain stimulation imposes complex informational lesions. PLoS One 8:e74462. CrossRef Medline

Aleksandrova LR, Creed MC, Fletcher PJ, Lobo DS, Hamani C, Nobrega JN (2013) Deep brain stimulation of the subthalamic nucleus increases premature responding in a rat gambling task. Behav Brain Res 245:76-82. CrossRef Medline

Alvarez L, Macias R, Guridi J, Lopez G, Alvarez E, Maragoto C, Teijeiro J, Torres A, Pavon N, Rodríguez-Oroz MC, Ochoa L, Hetherington H, Juncos J, DeLong MR, Obeso JA (2001) Dorsal subthalamotomy for Parkinson's disease. Mov Disord 16:72-78. CrossRef Medline

Alvarez L, Macias R, Lopez G, Alvarez E, Pavon N, Rodríguez-Oroz MC, Juncos JL, Maragoto C, Guridi J, Litvan I, Tolosa ES, Koller W, Vitek J, DeLong MR, Obeso JA (2005) Bilateral subthalamotomy in Parkinson's disease: initial and long-term response. Brain 128:570-583. CrossRef Medline

Baraduc P, Thobois S, Gan J, Broussolle E, Desmurget M (2013) A common optimization principle for motor execution in healthy subjects and parkinsonian patients. J Neurosci 33:665-677. CrossRef Medline

Bar-Gad I, Turner RS (2009) Stimulation effect on neuronal activity in the globus pallidus of the behaving macaque. In: Basal ganglia IX (Groenewegen H, Voorn P, Berendse H, Mulder A, Cools A, eds), pp 73-83. New York: Springer.

Bar-Gad I, Elias S, Vaadia E, Bergman H (2004) Complex locking rather than complete cessation of neuronal activity in the globus pallidus of a 1-methyl-4-phenyl-1,2,3,6-tetrahydropyridine-treated primate in response to pallidal microstimulation. J Neurosci 24:7410-7419. CrossRef Medline

Baunez C, Nieoullon A, Amalric M (1995) In a rat model of parkinsonism, lesions of the subthalamic nucleus reverse increases of reaction time but induce a dramatic premature responding deficit. J Neurosci 15:65316541. Medline

Benazzouz A, Gao DM, Ni ZG, Piallat B, Bouali-Benazzouz R, Benabid AL (2000) Effect of high-frequency stimulation of the subthalamic nucleus on the neuronal activities of the substantia nigra pars reticulata and ventrolateral nucleus of the thalamus in the rat. Neuroscience 99:289-295. CrossRef Medline

Bergman H, Wichmann T, Karmon B, DeLong MR (1994) The primate subthalamic nucleus: II. Neuronal activity in the MPTP model of parkinsonism. J Neurophysiol 72:507-520. Medline

Beurrier C, Bezard E, Bioulac B, Gross C (1997) Subthalamic stimulation elicits hemiballismus in normal monkey. Neuroreport 8:1625-1629. CrossRef Medline

Boraud T, Bezard E, Bioulac B, Gross CE (2000) Ratio of inhibited-toactivated pallidal neurons decreases dramatically during passive limb movement in the MPTP-treated monkey. J Neurophysiol 83:1760-1763. Medline 
Brown P, Mazzone P, Oliviero A, Altibrandi MG, Pilato F, Tonali PA, Di Lazzaro V (2004) Effects of stimulation of the subthalamic area on oscillatory pallidal activity in Parkinson's disease. Exp Neurol 188:480-490. CrossRef Medline

Brown RG, Jahanshahi M, Limousin-Dowsey P, Thomas D, Quinn NP, Rothwell JC (2003) Pallidotomy and incidental sequence learning in Parkinson's disease. Neuroreport 14:21-24. CrossRef Medline

Burnham KP, Anderson DR (2002) Model selection and multimodel inference: a practical information-theoretic approach. New York: Springer.

Carbon M, Eidelberg D (2006) Functional imaging of sequence learning in Parkinson's disease. J Neurol Sci 248:72-77. CrossRef Medline

Carlson JD, Cleary DR, Cetas JS, Heinricher MM, Burchiel KJ (2010) Deep brain stimulation does not silence neurons in subthalamic nucleus in Parkinson's patients. J Neurophysiol 103:962-967. CrossRef Medline

Chiken S, Nambu A (2013) High-frequency pallidal stimulation disrupts information flow through the pallidum by GABAergic inhibition. J Neurosci 33:2268-2280. CrossRef Medline

Cleary DR, Raslan AM, Rubin JE, Bahgat D, Viswanathan A, Heinricher MM, Burchiel KJ (2013) Deep brain stimulation entrains local neuronal firing in human globus pallidus internus. J Neurophysiol 109:978-987. CrossRef Medline

Creed MC, Hamani C, Nobrega JN (2013) Effects of repeated deep brain stimulation on depressive- and anxiety-like behavior in rats: comparing entopeduncular and subthalamic nuclei. Brain Stimul 6:506-514. CrossRef Medline

DeLong MR (1971) Activity of pallidal neurons during movement. J Neurophysiol 34:414-427. Medline

Desmurget M, Turner RS (2008) Testing basal ganglia motor functions through reversible inactivations in the posterior internal globus pallidus. J Neurophysiol 99:1057-1076. CrossRef Medline

Dorval AD (2008) Probability distributions of the logarithm of interspike intervals yield accurate entropy estimates from small datasets. J Neurosci Methods 173:129-139. CrossRef Medline

Dorval AD (2011) Estimating neuronal information: logarithmic binning of neuronal inter-spike intervals. Entropy (Basel) 13:485-501. CrossRef Medline

Dorval AD, Grill WM (2014) Deep brain stimulation of the subthalamic nucleus reestablishes neuronal information transmission in the 6-OHDA rat model of parkinsonism. J Neurophysiol 111:1949-1959. CrossRef Medline

Dorval AD, Russo GS, Hashimoto T, Xu W, Grill WM, Vitek JL (2008) Deep brain stimulation reduces neuronal entropy in the MPTP-primate model of Parkinson's disease. J Neurophysiol 100:2807-2818. CrossRef Medline

Dorval AD, Panjwani N, Qi RY, Grill WM (2009) Deep brain stimulation that abolishes Parkinsonian activity in basal ganglia improves thalamic relay fidelity in a computational circuit. Conf Proc IEEE Eng Med Biol Soc 2009:4230-4233. CrossRef Medline

Dorval AD, Kuncel AM, Birdno MJ, Turner DA, Grill WM (2010) Deep brain stimulation alleviates parkinsonian bradykinesia by regularizing pallidal activity. J Neurophysiol 104:911-921. CrossRef Medline

Dostrovsky JO, Levy R, Wu JP, Hutchison WD, Tasker RR, Lozano AM (2000) Microstimulation-induced inhibition of neuronal firing in human globus pallidus. J Neurophysiol 84:570-574. Medline

Esselink RA, de Bie RM, de Haan RJ, Lenders MW, Nijssen PC, Staal MJ, Smeding HM, Schuurman PR, Bosch DA, Speelman JD (2004) Unilateral pallidotomy versus bilateral subthalamic nucleus stimulation in PD: a randomized trial. Neurology 62:201-207. CrossRef Medline

Filion M, Tremblay L, Bédard PJ (1988) Abnormal influences of passive limb movement on the activity of globus pallidus neurons in parkinsonian monkeys. Brain Res 444:165-176. CrossRef Medline

Filion M, Tremblay L, Bedard PJ (1989) Excessive and unselective responses of medial pallidal neurons to both passive movements and striatal stitmulation in monkeys with MPTP-induced parkinsonism. London: John Libbey.

Franco V, Turner RS (2012) Testing the contributions of striatal dopamine loss to the genesis of parkinsonian signs. Neurobiol Dis 47:114-125. CrossRef Medline

Garcia L, Audin J, D’Alessandro G, Bioulac B, Hammond C (2003) Dual effect of high-frequency stimulation on subthalamic neuron activity. J Neurosci 23:8743-8751. Medline

Garcia L, D’Alessandro G, Fernagut PO, Bioulac B, Hammond C (2005) Impact of high-frequency stimulation parameters on the pattern of dis- charge of subthalamic neurons. J Neurophysiol 94:3662-3669. CrossRef Medline

Grill WM, Snyder AN, Miocinovic S (2004) Deep brain stimulation creates an informational lesion of the stimulated nucleus. Neuroreport 15:11371140. CrossRef Medline

Guo Y, Rubin JE, McIntyre CC, Vitek JL, Terman D (2008) Thalamocortical relay fidelity varies across subthalamic nucleus deep brain stimulation protocols in a data-driven computational model. J Neurophysiol 99: 1477-1492. CrossRef Medline

Hamada I, DeLong MR (1992) Excitotoxic acid lesions of the primate subthalamic nucleus result in transient dyskinesias of the contralateral limbs. J Neurophysiol 68:1850-1858. Medline

Hamani C, Saint-Cyr JA, Fraser J, Kaplitt M, Lozano AM (2004) The subthalamic nucleus in the context of movement disorders. Brain 127:4-20. CrossRef Medline

Hashimoto T, Elder CM, Okun MS, Patrick SK, Vitek JL (2003) Stimulation of the subthalamic nucleus changes the firing pattern of pallidal neurons. J Neurosci 23:1916-1923. Medline

Hayashi R, Hashimoto T, Tada T, Ikeda S (2003) Effects of unilateral pallidotomy on voluntary movement, and simple and choice reaction times in Parkinson's disease. Mov Disord 18:515-523. CrossRef Medline

Hershey T, Campbell MC, Videen TO, Lugar HM, Weaver PM, Hartlein J, Karimi M, Tabbal SD, Perlmutter JS (2010) Mapping Go-No-Go performance within the subthalamic nucleus region. Brain 133:3625-3634. CrossRef Medline

Jahanshahi M, Obeso I, Baunez C, Alegre M, Krack P (2014) Parkinson's disease, the subthalamic nucleus, inhibition, and impulsivity. Mov Disord. Advance online publication. Retrieved Oct 9, 2014. doi: 10.1002/ mds.26049. CrossRef Medline

Kaminer J, Thakur P, Evinger C (2014) Frequency matters: beta-band subthalamic nucleus deep-brain stimulation induces Parkinsonian-like blink abnormalities in normal rats. Eur J Neurosci 40:3237-3242. CrossRef Medline

Kühn AA, Kempf F, Brücke C, Gaynor Doyle L, Martinez-Torres I, Pogosyan A, Trottenberg T, Kupsch A, Schneider GH, Hariz MI, Vandenberghe W, Nuttin B, Brown P (2008) High-frequency stimulation of the subthalamic nucleus suppresses oscillatory beta activity in patients with Parkinson's disease in parallel with improvement in motor performance. J Neurosci 28:6165-6173. CrossRef Medline

Levy R, Ashby P, Hutchison WD, Lang AE, Lozano AM, Dostrovsky JO (2002) Dependence of subthalamic nucleus oscillations on movement and dopamine in Parkinson's disease. Brain 125:1196-1209. CrossRef Medline

Limousin P, Pollak P, Benazzouz A, Hoffmann D, Broussolle E, Perret JE, Benabid AL (1995) Bilateral subthalamic nucleus stimulation for severe Parkinson's disease. Mov Disord 10:672-674. CrossRef Medline

Martin RF, Bowden DM (1996) A stereotaxic template atlas of the macaque brain for digital imaging and quantitative neuroanatomy. Neuroimage 4:119-150. CrossRef Medline

McCairn KW, Turner RS (2009) Deep brain stimulation of the globus pallidus internus in the parkinsonian primate: local entrainment and suppression of low-frequency oscillations. J Neurophysiol 101:1941-1960. CrossRef Medline

McConnell GC, So RQ, Hilliard JD, Lopomo P, Grill WM (2012) Effective deep brain stimulation suppresses low-frequency network oscillations in the basal ganglia by regularizing neural firing patterns. J Neurosci 32: 15657-15668. CrossRef Medline

Meissner W, Leblois A, Hansel D, Bioulac B, Gross CE, Benazzouz A, Boraud T (2005) Subthalamic high frequency stimulation resets subthalamic firing and reduces abnormal oscillations. Brain 128:2372-2382. CrossRef Medline

Merello M, Perez-Lloret S, Antico J, Obeso JA (2006) Dyskinesias induced by subthalamotomy in Parkinson's disease are unresponsive to amantadine. J Neurol Neurosurg Psychiatry 77:172-174. CrossRef Medline

Merello M, Tenca E, Pérez Lloret S, Martín ME, Bruno V, Cavanagh S, Antico J, Cerquetti D, Leiguarda R (2008) Prospective randomized 1-year follow-up comparison of bilateral subthalamotomy versus bilateral subthalamic stimulation and the combination of both in Parkinson's disease patients: a pilot study. Br J Neurosurg 22:415-422. CrossRef Medline

Miocinovic S, Parent M, Butson CR, Hahn PJ, Russo GS, Vitek JL, McIntyre CC (2006) Computational analysis of subthalamic nucleus and lenticu- 
lar fasciculus activation during therapeutic deep brain stimulation. J Neurophysiol 96:1569-1580. CrossRef Medline

Miocinovic S, Zhang J, Xu W, Russo GS, Vitek JL, McIntyre CC (2007) Stereotactic neurosurgical planning, recording, and visualization for deep brain stimulation in non-human primates. J Neurosci Methods 162:32-41. CrossRef Medline

Moran A, Bar-Gad I (2010) Revealing neuronal functional organization through the relation between multi-scale oscillatory extracellular signals. J Neurosci Methods 186:116-129. CrossRef Medline

Moran A, Bergman H, Israel Z, Bar-Gad I (2008) Subthalamic nucleus functional organization revealed by parkinsonian neuronal oscillations and synchrony. Brain 131:3395-3409. CrossRef Medline

Moran A, Stein E, Tischler H, Belelovsky K, Bar-Gad I (2011) Dynamic stereotypic responses of basal ganglia neurons to subthalamic nucleus high-frequency stimulation in the parkinsonian primate. Front Syst Neurosci 5:21. CrossRef Medline

Moran A, Stein E, Tischler H, Bar-Gad I (2012) Decoupling neuronal oscillations during subthalamic nucleus stimulation in the parkinsonian primate. Neurobiol Dis 45:583-590. CrossRef Medline

Nambu A, Tokuno H, Hamada I, Kita H, Imanishi M, Akazawa T, Ikeuchi Y, Hasegawa N (2000) Excitatory cortical inputs to pallidal neurons via the subthalamic nucleus in the monkey. J Neurophysiol 84:289-300. Medline

Nambu A, Tokuno H, Takada M (2002) Functional significance of the cortico-subthalamo-pallidal 'hyperdirect' pathway. Neurosci Res 43:111117. CrossRef Medline

Obeso JA, Jahanshahi M, Alvarez L, Macias R, Pedroso I, Wilkinson L, Pavon N, Day B, Pinto S, Rodríguez-Oroz MC, Tejeiro J, Artieda J, Talelli P, Swayne O, Rodríguez R, Bhatia K, Rodriguez-Diaz M, Lopez G, Guridi J, Rothwell JC (2009) What can man do without basal ganglia motor output? The effect of combined unilateral subthalamotomy and pallidotomy in a patient with Parkinson's disease. Exp Neurol 220:283-292. CrossRef Medline

Panzeri S, Senatore R, Montemurro MA, Petersen RS (2007) Correcting for the sampling bias problem in spike train information measures. J Neurophysiol 98:1064-1072. CrossRef Medline

Pasquereau B, Turner RS (2013) Limited encoding of effort by dopamine neurons in a cost-benefit trade-off task. J Neurosci 33:8288-8300. CrossRef Medline

Pasquereau B, Nadjar A, Arkadir D, Bezard E, Goillandeau M, Bioulac B, Gross CE, Boraud T (2007) Shaping of motor responses by incentive values through the basal ganglia. J Neurosci 27:1176-1183. CrossRef Medline

Ray NJ, Jenkinson N, Brittain J, Holland P, Joint C, Nandi D, Bain PG, Yousif N, Green A, Stein JS, Aziz TZ (2009) The role of the subthalamic nucleus in response inhibition: evidence from deep brain stimulation for Parkinson's disease. Neuropsychologia 47:2828-2834. CrossRef Medline

Raz A, Vaadia E, Bergman H (2000) Firing patterns and correlations of spontaneous discharge of pallidal neurons in the normal and the tremulous 1-methyl-4-phenyl-1,2,3,6-tetrahydropyridine vervet model of parkinsonism. J Neurosci 20:8559-8571. Medline

Reese R, Leblois A, Steigerwald F, Pötter-Nerger M, Herzog J, Mehdorn HM, Deuschl G, Meissner WG, Volkmann J (2011) Subthalamic deep brain stimulation increases pallidal firing rate and regularity. Exp Neurol 229: 517-521. CrossRef Medline
Rodríguez-Oroz MC, Obeso JA, Lang AE, Houeto JL, Pollak P, Rehncrona S, Kulisevsky J, Albanese A, Volkmann J, Hariz MI, Quinn NP, Speelman JD, Guridi J, Zamarbide I, Gironell A, Molet J, Pascual-Sedano B, Pidoux B, Bonnet AM, Agid Y, et al. (2005) Bilateral deep brain stimulation in Parkinson's disease: a multicentre study with 4 years follow-up. Brain 128:2240-2249. CrossRef Medline

Rosenbaum R, Zimnik A, Zheng F, Turner RS, Alzheimer C, Doiron B, Rubin JE (2014) Axonal and synaptic failure suppress the transfer of firing rate oscillations, synchrony and information during high frequency deep brain stimulation. Neurobiol Dis 62:86-99. CrossRef Medline

Rubin JE, McIntyre CC, Turner RS, Wichmann T (2012) Basal ganglia activity patterns in parkinsonism and computational modeling of their downstream effects. Eur J Neurosci 36:2213-2228. CrossRef Medline

Slavin KV, Baumann TK, Burchiel KJ (2004) Treatment of hemiballismus with stereotactic pallidotomy: case report and review of the literature. Neurosurg Focus 17:E7. Medline

Soares J, Kliem MA, Betarbet R, Greenamyre JT, Yamamoto B, Wichmann T (2004) Role of external pallidal segment in primate parkinsonism: comparison of the effects of 1-methyl-4-phenyl-1,2,3,6-tetrahydropyridineinduced parkinsonism and lesions of the external pallidal segment. J Neurosci 24:6417-6426. CrossRef Medline

Strong SP, de Ruyter van Steveninck RR, Bialek W, Koberle R (1998) On the application of information theory to neural spike trains. Pac Symp Biocomput 1998:621-632. Medline

Tachibana Y, Kita H, Chiken S, Takada M, Nambu A (2008) Motor cortical control of internal pallidal activity through glutamatergic and GABAergic inputs in awake monkeys. Eur J Neurosci 27:238-253. CrossRef Medline

Tai CH, Boraud T, Bezard E, Bioulac B, Gross C, Benazzouz A (2003) Electrophysiological and metabolic evidence that high-frequency stimulation of the subthalamic nucleus bridles neuronal activity in the subthalamic nucleus and the substantia nigra reticulata. FASEB J 17:1820-1830. CrossRef Medline

Turner RS, DeLong MR (2000) Corticostriatal activity in primary motor cortex of the macaque. J Neurosci 20:7096-7108. Medline

Turner RS, Anderson ME (1997) Pallidal discharge related to the kinematics of reaching movements in two dimensions. J Neurophysiol 77:10511074. Medline

Wichmann T, Bergman H, DeLong MR (1994) The primate subthalamic nucleus: III. Changes in motor behavior and neuronal activity in the internal pallidum induced by subthalamic inactivation in the MPTP model of parkinsonism. J Neurophysiol 72:521-530. Medline

Wichmann T, Bergman H, Starr PA, Subramanian T, Watts RL, DeLong MR (1999) Comparison of MPTP-induced changes in spontaneous neuronal discharge in the internal pallidal segment and in the substantia nigra pars reticulata in primates. Exp Brain Res 125:397-409. CrossRef Medline

Wilson CJ, Beverlin B 2nd, Netoff T (2011) Chaotic desynchronization as the therapeutic mechanism of deep brain stimulation. Front Syst Neurosci 5:50. CrossRef Medline

Wodarg F, Herzog J, Reese R, Falk D, Pinsker MO, Steigerwald F, Jansen O, Deuschl G, Mehdorn HM, Volkmann J (2012) Stimulation site within the MRI-defined STN predicts postoperative motor outcome. Mov Disord 27:874-879. CrossRef Medline 